Manfred Naumann

Stendhals Deutschland

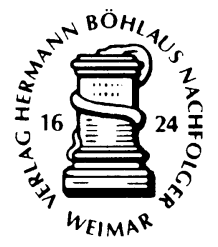




\author{
Manfred Naumann
}

\title{
Stendhals Deutschland
}

\author{
Impressionen über Land und Leute
}


Die Deutsche Bibliothek - CIP-Einheitsaufnahme

Naumann, Manfred:

Stendhals Deutschland: Impressionen über Land und Leute /

Manfred Naumann.

- Weimar : Verlag Hermann Böhlaus Nachfolger, 2001

ISBN 978-3-7400-1136-9

ISBN 978-3-7400-1136-9

ISBN 978-3-476-02709-2 (eBook)

DOI 10.1007/978-3-476-02709-2

Dieses Werk einschließlich aller seiner Teile ist urheberrechtlich geschützt. Jede Verwertung außerhalb der engen Grenzen des Urheberrechtsgesetzes ist ohne $\mathrm{Zu}$ stimmung des Verlages unzulässig und strafbar. Das gilt insbesondere für Vervielfältigungen, Übersetzungen, Mikroverfilmungen und die Einspeicherung und Verarbeitung in elektronischen Systemen.

(C) 2001 Springer-Verlag GmbH Deutschland

Ursprünglich erschienen bei Verlag Hermann Böhlaus Nachfolger Weimar 2001

www.boehlausnf.de

info@boehlausnf.de 


\section{Inhalt}

Vorbemerkung 1

Henri Beyle alias Stendhal 3

Auf Namenssuche 3 Schreib- und Sprechstrategien 12 Kindheitsmuster 18

Eintritt ins Weltgeschehen 27

Anprobe einer Uniform 27 Texte ohne Publikum 33 Rückzüge vom literarischen Schlachtfeld 43

Vorübungen in deutscher Landeskunde 57

Einführungen 57 Lese- und Theaterfreuden bei Kotzebue, August Lafontaine und Timotheus Hermes 71 Die Leiden Werthers 80 Mit Mirabeau und Thiébault zu Besuch in Berlin 84 In der Schule Friedrichs des Großen 96 Geschichte bei Ancillon, einem Berliner Hugenotten 109

Engagements im Königreich Westfalen 117

Vorsprechen am Brandenburger Tor und Ankunft in Braunschweig 117 Nachrufe auf Herzog Karl Wilhelm Ferdinand 125 Mit Denon, dem LouvreDirektor, in der Bibliothek von Wolfenbüttel und in Braunschweiger Museen 130 Verwaltungsroutine 139 Kulturgüter 160 Deutsch-französiche Freundschaften: Karl Friedrich von Strombeck und Philippine von Bülow 175 Liebe in Braunschweig: Wilhelmine von Griesheim 189

Bei Haydn und Mozart in Wien 210

Touristenreise nach Ingolstadt 210 Besichtigung von Kriegsschauplätzen 214 Hinter den Linien von Aspern und Wagram 218 Musikfestspiele 224 Kristallisationen 233

Quer durch Deutschland nach Rußland und zurück 242

Im gehobenen Staatsdienst 242 Blicke auf das Schloß Belvedere in Weimar 247 Von Weimar nach Moskau 250 Erholungspause in Königsberg 253

In den Bildergalerien von Dresden 260

Vom Japanischen Palais in die Schlacht von Bautzen 260 Ein Abstecher ins schlesische, jetzt polnische Sagan 264 Vor den Dresdner Gemälden Correggios 269

$\mathrm{Zu}$ Gast in Goethes Haus 279

Außer Dienst 279 Streitereien mit August Wilhelm Schlegel und Madame de Staël 280 Ein toleranter deutscher Geheimrat 287 Abschiedsszenen 297

Nachbemerkung 300

Anhang 301

Anmerkungen 302 Literaturverzeichnis 336 Werke Stendhals 348 Zeitschriftenregister 349 Personenregister 350 Ortsregister 360 


\section{Vorbemerkung}

Die um Stendhal gescharte internationale Forschergemeinschaft, die sich seit 1955 in regelmäßigen Abständen auf Kongressen trifft, hat sich auf deutschem Boden bisher dreimal versammelt: 1978 in Braunschweig, 1982 in Mainz und 1992 in Stendal.

Sie trug damit der Tatsache Rechnung, daß Stendhal auch in Deutschland seine Gemeinde hat: Forscher, die ihm gelehrte Studien widmen, Übersetzer, die seine Werke ins Deutsche übertragen, Verlage, die sie herausgeben, Kritiker, die sie kommentieren, und nicht zuletzt die nicht professionellen Leser, die nun schon seit vielen Jahrzehnten immer wieder nach Büchern von Stendhal verlangen, weil sie an ihrer Lektüre poetisches und intellektuelles Vergnügen finden oder von den Filmen bezaubert waren, in denen die Helden und Heldinnen aus Rot und Schwarz und aus der Kartause von Parma agieren.

Auf einem der drei Kongresse, dem in Braunschweig, stand das Thema »Stendhal und Deutschland « auf der Tagesordnung. Victor Del Litto, der Doyen des Stendhalschen Korps, der die Eröffnungsrede hielt, würdigte die diesbezüglichen Arbeiten und kam dabei zu dem Ergebnis, daß sie in zwei Richtungen weitergeführt werden sollten: Wie haben die deutschen Leser und Literaturwissenschaftler auf Stendhals Werk reagiert? Wie nahm Stendhal die Deutschen und ihre Kultur wahr, und was verdankte er ihnen?

Der Geschichte seiner Rezeption im Rahmen der geistigen und politischen Entwicklungen Deutschlands noch etwas genauer als bisher zu folgen wäre sicher ein lohnendes Thema. Ich habe mich für die andere Perspektive entschieden. Man weiß zwar, daß Stendhal im Gefolge Napoleons jahrelang in Deutschland unterwegs war, vieles von den Deutschen und über die Deutschen las und hörte, die Eindrücke zu Papier brachte und sie manchmal auch seiner Phantasie einverleibte. Mit Recht aber stellte Victor Del Litto fest, daß eine Studie, die Stendhals Bilder von den Gegenden und Menschen jenseits des Rheins untersucht, noch immer fehlt. Auf der Landkarte, die Stendhal von Deutschland entwirft, gibt es noch eine nicht unbeträchtliche Anzahl weißer Flecken. Dies und nicht zuletzt meine fast schon libidinöse Schwärmerei für Stendhal sind der Grund, weshalb ich mich auf das Schreibabenteuer eingelassen habe.

Es versteht sich, daß den "Stendhaliens « auch Mitteilungen begegnen werden, die ihnen nicht neu sind; ich habe ihre Informationen mit Dank entgegengenommen und die von mir benutzten Werke in den Anmerkungen und der Bibliographie verzeichnet. Wenn ich Stendhal zitiere, wird auf die Stellen in den französischen Werkausgaben verwiesen. Allerdings habe ich ihn - entgegen der Usancen in der Gelehrtenwelt nur in deutscher Übersetzung zu Wort kommen lassen, da mir auch ein allgemein interessiertes Lesepublikum vorschwebt, das durch Zitate in der Originalsprache nicht abgeschreckt werden sollte. Zur Debatte stehen die von Stendhal geführten Dialoge mit Deutschland; sie sind ein- 
gebettet in kulturelle Kommunikationsverhältnisse und Verständigungsprobleme, deren geschichtliche Komplikationen zwar glücklicherweise beigelegt, aber unterschwellig doch noch immer virulent sind, daher den engen Zirkel eruditiver Sprachregulierungen sprengen. Die von mir nacherzählten Gespräche mit Deutschland hat ein genialer, ja querdenkender Franzose vor nunmehr zweihundert Jahren geführt, und vieles, was er zu berichten weiß, wirkt heute vielleicht etwas befremdlich. Warum sollten Leser, die des Französischen nicht mächtig sind, aus dem Dialog mit Stendhal ausgeschlossen bleiben? Die Unterhaltung mit ihm könnte zweifelsohne das beiderseitige Verstehen fördern. 